УДК 623.418 .4

Сергій Михайлович Коротін (канд. техн. наук)

Юрій Миколайович Коломієць

Національний університет оборони Украйни імені Івана Черняховського, Київ, Украӥна

\title{
ПРОГНОЗНА МАТЕМАТИЧНА МОДЕЛЬ УПРАВЛІННЯ ГІПОТЕТИЧНОЮ ПЕРСПЕКТИВНОЮ КЕРОВАНОЮ АВІАЦІЙНОЮ РАКЕТОЮ
}

\begin{abstract}
Процес пошуку шляхів розроблення високо ефективної керованої авіаційної ракети, до того ж достатньо дешевої у виробництві, в останні п'ять років став предметом наукових досліджень науководослідних установ Міністерства оборони і державних підприємств оборонно-промислового комплексу України. Вважається, щзо одним із перспективних напрямів досліджень є прочес наведення такоі ракети на ціль противника в промені лазерного випромінювання. Результати проведеного аналізу бойових властивостей $i$ тактико-технічних характеристик прототипів, розроблених в провідних краӥнах світу, дали змогу авторам статті прийти до висновку щодо розроблення математичної моделі управління гіпотетичною перспективною керованою авіачійною ракетою в полі лазерного випромінювання. У наведеній статті представлена така модель, яка базується на вирішенні системи динамічних $і$ кінематичних диференціальних рівнянь. Застосування даної моделі дозволяє визначити вимоги до аеродинамічних, масо-інериійних характеристик ракети, удосконалити відомі алгоритми управління, розробити вимоги до складових частин системи управління $і$ зовнішнього контуру наведення та у подальшому коригувати алгоритм управління з урахуванням реально отриманих характеристик перспективної керованої авіаційної ракети, параметрів елементів системи управління $i$ контуру наведення.
\end{abstract}

Ключові слова: система управління, математична модель, алгоритм управління

\section{Вступ}

Бойова ефективність сучасного літального апарату визначається бойовими властивостями його бортового авіаційного комплексу, енергетичними параметрами силової установки, ергономікою тощо. Вважається, що основними бойовими властивостями бортового авіаційного комплексу є: забезпечення високого рівня безпеки польотів, багатоканальність застосування зброї, можливість одночасної атаки декількох повітряних цілей i наземних об’єктів противника високоточною зброєю, бойова ефективність бортового комплексу оборони.

Постановка проблеми. У країнах-членах НАТО широко застосовуються системи 3 керуванням ракетою в інформаційному полі лазерного випромінювання $[5,13,14]$. У Російській Федерації та республіці Білорусь знайшли спосіб, як захистити свій літальний апарат за допомогою бортового комплексу оборони [3, 10]. В Україні 3 початком антитерористичної операції на державних підприємствах оборонно-промислового комплексу модернізовано комплекси оптико-електронного придушення [1]. В той же час сучасні технології, що закладаються у розроблення нових зразків керованих ракет, дають можливість 3 досить високою імовірністю уражати літальні апарати [11, 12]. Отже, протистояти сучасним зразкам озброєння доволі складно. Тому, зважаючи на характер сучасного повітряного бою, авторами статті розглядається можливість дообладнання комплексу авіаційного озброєння бойового літака 3С України системою наведення, здатною наводити керовану авіаційну ракету (КАР) на ціль в автоматизованому режимі в полі лазерного випромінювання.

В статті розглядається математична модель системи автоматичного управління гіпотетичної перспективної КАР, наведення якої на ціль противника можливо буде здійснити 3 бойового літака у полі лазерного випромінювання.

Аналіз останніх досліджень і публікацій.

В роботах [6, 7] наведені результати теоретичних досліджень, 3 яких можна зробити висновки, що під час здійснення наведення ракети на ціль рух поля лазерного випромінювання узгоджений 3 рухом ракети. Просторова модуляція, принцип роботи якої детально розглянуто в [6], дозволяє бортовій системі управління ракети автоматично утримувати іiі в центрі сформованого променю.

Функціонування бортового комплексу авіаційного озброєння зводиться до вирішення завдань 3 визначення в кожний момент часу кутових координат своєї ракети та повітряної цілі до моменту іiі ураження, та наведення на неї КАР. В системі наведення такого комплексу авіаційного озброєння бортова інформаційно-вимірювальна система вирішує два основних завдання: визначає кутові координати ракети в інформаційному полі лазерного променю і положення ракети відносно земної поверхні (кут крену). Ця інформація дозволяє бортовий системі управління утримувати керовану авіаційну ракету в польоті поблизу центру лазерного променю [7].

При визначенні вимог до характеристик перспективної КАР та елементів, що входять в 
контур наведення, обранні структури і алгоритму роботи системи управління ракетою в практиці проектування використовують методи теорії алгоритмічного управління $[2,4,8,9]$.

Метою статті с описання математичної моделі управління гіпотетичною перспективною КАР. Застосування даної моделі дозволить визначити вимоги до аеродинамічних, масо-інерційних характеристик ракети, удосконалити алгоритм управління, розробити вимоги до складових частин системи управління і зовнішнього контуру наведення, визначати промах в певних умовах іiі застосування та визначити точність наведення на повітряну ціль.

\section{Виклад основного матеріалу дослідження}

Розглянемо спрощену схему контуру наведення КАР в промені лазерного випромінювання, рис. 1 [6].

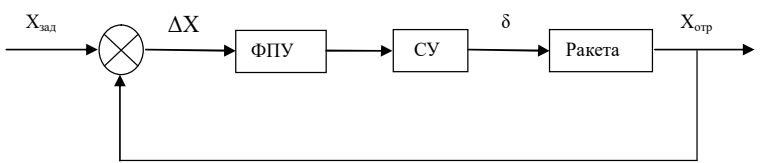

Рис. 1. Спрощена схема контуру наведення керованої авіаційної ракети у лазерному промені

Система наведення формує інформаційне поле, центр якого на запрограмованій відстані відповідає заданій координаті польоту за променем $\mathrm{X}_{\text {зад }}$.

Принцип дії такого контуру наведення детально описано в [6].

Очевидним $\epsilon$ те, що для визначення вимог до параметрів усіх елементів, що входять в цей замкнутий контур, i вибору алгоритму роботи системи управління необхідно знати динамічні характеристики КАР як об'єкту управління $[2,9]$.

Динамічні рівняння руху центру мас КАР відносно швидкісної системи координат мають такий вигляд $[6,9]$ :

$$
\begin{aligned}
\frac{\mathrm{dV}}{\mathrm{dt}} & =\frac{\left(\mathrm{R}_{\mathrm{t}} \cos \alpha_{\mathrm{p}}-\mathrm{Q}-\mathrm{mg} \sin \theta\right)}{\mathrm{m}} ; \\
\frac{\mathrm{d} \theta}{\mathrm{dt}} & =\frac{\left(\mathrm{Y}_{\mathrm{s}} \cos \gamma_{2}-\mathrm{Y}_{\mathrm{g}} \sin \gamma_{2}-\mathrm{mg} \cos \theta\right)}{\mathrm{mV}} ; \\
\frac{\mathrm{d} \psi}{\mathrm{dt}} & =-\frac{\left(\mathrm{Y}_{\mathrm{s}} \sin \gamma_{2}+\mathrm{Y}_{\mathrm{g}} \cos \gamma_{2}\right)}{\mathrm{mV} \cos \theta},
\end{aligned}
$$

де $\mathrm{m}$ - поточна маса; $\mathrm{V}$ - швидкість; $\mathrm{R}_{\mathrm{t}}-$ сила тяги маршового двигуна; $\alpha_{\mathrm{p}}-$ просторовий кут атаки (кут між подовжньою віссю і вектором швидкості ракети); Q - проекція повної аеродинамічної сили на вектор швидкості; $\mathrm{g}$ - прискорення вільного падіння; $\theta$ - кут нахилу траєкторії; $\gamma_{2}-$ кут повороту площини просторового кута атаки відносно швидкісної системи координат; $\mathrm{Y}_{\mathrm{s}}-$ проекція повної аеродинамічної сили на площину просторового кута атаки; $\mathrm{Y}_{\mathrm{g}}$ - проекція повної аеродинамічної сили на площину, що перпендикулярна площині просторового кута атаки; $\psi-$ кут оберту траєкторії.

Кінематичні рівняння руху центру мас КАР відносно земної системи координат мають такий вигляд:

$$
\begin{aligned}
& \frac{\mathrm{dx}}{\mathrm{dt}}=\mathrm{V} \cos \theta \cos \psi ; \\
& \frac{\mathrm{dy}}{\mathrm{dt}}=\mathrm{V} \sin \theta ; \\
& \frac{\mathrm{dz}}{\mathrm{dt}}=-\mathrm{V} \cos \Theta \sin \psi,
\end{aligned}
$$

де $\mathrm{x}, \mathrm{y}, \mathrm{z}$ - координати центра ваги ракети в земній декартовій системі координат.

Динамічні рівняння обертального руху КАР відносно зв'язаної системи координат мають вигляд:

$$
\begin{aligned}
& \frac{d \omega_{x}}{d t}=\frac{M_{x}-\left(J_{z}-J_{y}\right) \omega_{z} \omega_{y}}{J_{x}} ; \\
& \frac{d \omega_{y}}{d t}=\frac{M_{y}-\left(J_{x}-J_{z}\right) \omega_{x} \omega_{y}}{J_{y}} ; \\
& \frac{d \omega_{z}}{d t}=\frac{M_{z}-\left(J_{y}-J_{x}\right) \omega_{y} \omega_{x}}{J_{z}}
\end{aligned}
$$

де $\omega_{\mathrm{x}}, \omega_{\mathrm{y}}, \omega_{\mathrm{z}}-$ проекції вектору кутової швидкості ракети на вісі зв'язаної системи координат;

$\mathrm{M}_{\mathrm{x}}, \mathrm{M}_{\mathrm{y}}, \mathrm{M}_{\mathrm{z}}$ - проекції моментів усіх зовнішніх сил на вісі зв'язаної системи координат;

$\mathrm{J}_{\mathrm{x}}, \mathrm{J}_{\mathrm{y}}, \mathrm{J}_{\mathrm{z}}$ - моменти інерції ракети відносно вісей зв'язаної системи координат.

Кінематичні рівняння, що описують обертання КАР відносно земної системи координат, мають наступний вигляд:

$$
\begin{aligned}
& \frac{\mathrm{d} \psi}{\mathrm{dt}}=\frac{\left.\omega_{\mathrm{y}} \cos \gamma-\omega_{\mathrm{z}} \sin \gamma\right)}{\cos \vartheta} ; \\
& \frac{\mathrm{d} \vartheta}{\mathrm{dt}}=\omega_{\mathrm{y}} \sin \gamma+\omega_{\mathrm{z}} \cos \gamma ; \\
& \frac{\mathrm{d} \gamma}{\mathrm{dt}}=\omega_{\mathrm{x}}-\sin \vartheta \frac{\left(\omega_{\mathrm{y}} \cos \gamma-\omega_{\mathrm{z}} \sin \gamma\right)}{\cos \vartheta},
\end{aligned}
$$

де $\psi, \vartheta, \gamma-$ відповідно кут рискання, тангажу та крену ракети.

Геометричні відношення, що описують зв'язок між кутами $\Psi, \Theta, \gamma_{c}, \gamma_{2}$ та кутами $\psi, \vartheta$, $\gamma, \alpha, \beta, \alpha_{\mathrm{p}}, \gamma_{\mathrm{p}}$, мають наступний вигляд:

$\sin \alpha=\sec \beta(\sin \vartheta \cos (\Psi-\psi)+$

$+\sin \gamma \sin (\Psi-\psi)) \cos \Theta-\cos \vartheta \cos \gamma \sin \Theta)$;

$\sin \beta=(\sin \vartheta \sin \gamma \cos (\Psi-\psi)-$

$-\cos \gamma \sin (\Psi-\psi)) \cos \Theta-\cos \vartheta \sin \gamma \sin \Theta)$;

$\sin \gamma_{\mathrm{c}}=\cos \alpha \cos (\Psi-\psi) \sin \gamma+$

$+(\sin \alpha \cos \vartheta-\cos \alpha \sin \vartheta \cos \gamma) \sin (\Psi-\psi)$;

$\operatorname{tg} \gamma_{2}=\frac{\sin \alpha \sin \gamma_{c}-\cos \alpha \sin \beta \cos \gamma_{c}}{\sin \alpha \cos \gamma_{c}+\cos \alpha \sin \beta \sin \gamma_{c}} ;$

$\cos \alpha_{\mathrm{p}}=\cos \alpha \cos \beta$;

$\operatorname{tg} \gamma_{p}=\frac{\sin \beta}{\sin \alpha \cos \beta}$.

Диференціальне рівняння, що описує зміну маси КАР, має вигляд:

$$
\frac{\mathrm{dm}}{\mathrm{dt}}=-\mathrm{m}_{\mathrm{c}},
$$

де $\mathrm{m}_{\mathrm{c}}$ - щосекундна витрата палива.

Для того, щоб дана система рівнянь була замкнутою, необхідно задати відхилення органів управління як функцію часу або додати рівняння, 
що описують процеси формування заданих відхилень цих органів, 3 урахуванням змін аеродинамічних сил і моментів, що відповідають цим відхиленням.

Вирішуючи систему рівнянь (1)-(6) численним інтегруванням, можна визначити усі параметри руху ракети і здійснити математичне моделювання керованого польоту КАР.

Для застосування методів теорії автоматичного управління необхідно описати ракету як динамічну ланку, тобто отримати передаточні функції параметрів руху за певним управляючим збурюючим впливом $[2,4,8]$.

Для лінеаризації системи рівнянь (1)-(6) застосовується метод "заморожування" коефіцієнтів, що дозволяє описати ракету як динамічну ланку, що має змінні параметри, які залежать від поточних умов польоту. Детально методика лінеаризації рівнянь руху ракети приведена в роботах $[2,9]$. При відхиленні органів управління ракета виходить на певний кут атаки, внаслідок чого створюється нормальне прискорення і змінюється траєкторія польоту.

Оскільки ракети такого класу можна розглядати як вісесиметричні, то, без урахування сили тяжіння, рівняння, що описують поздовжній i поперечний рух ракети, будуть подібні.

Рівняння, що описують поздовжній рух ракети, після лінеаризації i припущень мають такий вигляд:

$$
\begin{aligned}
& \frac{\mathrm{d}^{2} \vartheta}{\mathrm{dt}^{2}}=\frac{\left(\mathrm{M}_{\mathrm{z}}^{\omega_{\mathrm{z}}} \frac{\mathrm{d} \vartheta}{\mathrm{dt}}+\mathrm{M}_{\mathrm{z}}^{\alpha} \frac{\mathrm{d} \alpha}{\mathrm{dt}}+\mathrm{M}_{\mathrm{z}}^{\alpha} \alpha-\mathrm{M}_{\mathrm{z}}^{\delta} \delta\right)}{\mathrm{J}_{\mathrm{z}}} ; \\
& \frac{\mathrm{d} \Theta}{\mathrm{dt}}=\frac{\left(\mathrm{C}_{\mathrm{y}}^{\delta} \delta+\left(\mathrm{R}+\mathrm{C}_{\mathrm{y}}^{\alpha}\right) \alpha\right)}{\mathrm{mV}} ; \alpha=\Theta-\vartheta,
\end{aligned}
$$

де $\mathrm{M}_{\mathrm{z}}^{\delta}=\mathrm{m}_{\mathrm{z}}^{\delta} \mathrm{S}_{\mathrm{xap}} \mathrm{L}_{\mathrm{xap}} \frac{\rho \mathrm{V}^{2}}{2}-$ похідна моменту тангажу по куту відхилення рулів; $\rho$ - щільність повітря; V - швидкість польоту ракети; $\mathrm{S}_{\text {хар }}$ - характерна площа; $\mathrm{L}_{\text {хар }}-$ характерний лінійний розмір; $\mathrm{M}_{\mathrm{z}}^{\omega_{\mathrm{z}}}$ - похідна моменту тангажу по кутовій швидкості; $\mathrm{M}_{\mathrm{z}}^{\alpha}=\mathrm{m}_{\mathrm{z}}^{\alpha} \mathrm{S}_{\mathrm{xap}} \mathrm{L}_{\mathrm{xap}} \frac{\rho \mathrm{V}^{2}}{2}$ похідна моменту тангажу по куту атаки; $\mathrm{m}_{\mathrm{z}}^{\alpha}$ - похідна коефіцієнта моменту тангажу по куту атаки; $\mathrm{M}_{\mathrm{z}}^{\omega_{\mathrm{z}}}=\mathrm{m}_{\mathrm{z}}^{\omega_{\mathrm{z}}} \mathrm{S}_{\mathrm{xap}} \mathrm{L}_{\mathrm{xap}} \frac{\rho \mathrm{V}^{2}}{2}-$ похідна моменту тангажу по кутовій швидкості тангажу; $\mathrm{m}_{\mathrm{Z}}^{\omega_{\mathrm{z}}}$ - похідна коефіцієнта моменту тангажу по кутовій швидкості тангажу; $\mathrm{M}_{\mathrm{z}}^{\alpha}=\mathrm{m}_{\mathrm{z}}^{\alpha} \mathrm{S}_{\text {хар }} \mathrm{L}_{\text {хар }} \frac{\rho \mathrm{V}^{2}}{2}-$ похідна моменту тангажу по швидкості зміни кута атаки; $\mathrm{m}_{\mathrm{z}}^{\alpha}$ - похідна коефіцієнта моменту тангажу по швидкості зміни кута атаки; $\mathrm{C}_{\mathrm{y}}^{\delta}=\mathrm{c}_{\mathrm{y}}^{\delta} \mathrm{S}_{\mathrm{xap}} \frac{\rho \mathrm{V}^{2}}{2}-$ похідна підйомної сили по куту відхилення рулів; $\mathrm{c}_{\mathrm{y}}^{\delta}-$ похідна коефіцієнта підйомної сили по куту відхилення рулів; $\mathrm{C}_{\mathrm{y}}^{\alpha}=\mathrm{c}_{\mathrm{y}}^{\alpha} \mathrm{S}_{\mathrm{xap}} \frac{\rho \mathrm{V}^{2}}{2}-$ похідна підйомної сили по куту атаки; $\mathrm{c}_{\mathrm{y}}^{\alpha}-$ похідна коефіцієнта підйомної сили по куту атаки.

Iз системи рівнянь (7) можна отримати наступну передаточну функцію, що характеризує реакцію поперечного прискорення ракети 3 на відхилення рулів $[2,4,6]$ :

$$
\mathrm{M}_{\delta}^{\ddot{y}}=K \frac{\left(\mathrm{T}_{1} \mathrm{P}+1\right)\left(\mathrm{T}_{2} \mathrm{P}+1\right)}{\mathrm{T}_{\alpha}^{2} \mathrm{P}^{2}+2 \xi \mathrm{T}_{\alpha} \mathrm{P}+1},
$$

де

$$
\begin{aligned}
& K=V \frac{M_{z}^{\delta}\left(R+C_{y}^{\alpha}\right)-M_{z}^{\alpha} C_{y}^{\delta}}{m V M_{z}^{\alpha}-M_{z}^{\omega_{z}}\left(R+C_{y}^{\alpha}\right)} ; \\
& \mathrm{T}_{\alpha}=\sqrt{\frac{\mathrm{J}_{\mathrm{z}}}{-\mathrm{M}_{\mathrm{z}}^{\alpha}-\mathrm{M}_{\mathrm{z}}^{\omega_{\mathrm{z}}} \frac{\left(\mathrm{R}+\mathrm{C}_{\mathrm{y}}^{\alpha}\right)}{\mathrm{mV}}}} ; \\
& \xi=\frac{-\frac{\mathrm{M}_{\mathrm{z}}^{\omega_{\mathrm{z}}}+\mathrm{M}_{\mathrm{z}}^{\alpha}}{\mathrm{J}_{\mathrm{z}}}+\frac{\left(\mathrm{R}+\mathrm{C}_{\mathrm{y}}^{\alpha}\right)}{\mathrm{mV}}}{\sqrt[2]{-\frac{\mathrm{M}_{\mathrm{z}}^{\alpha}}{\mathrm{J}_{\mathrm{z}}}}} ; \\
& \mathrm{T}_{1}=\mathrm{D}+\sqrt{\mathrm{C}+\mathrm{D}^{2}} ; \mathrm{T}_{2}=\mathrm{D}-\sqrt{\mathrm{C}+\mathrm{D}^{2}} ; \\
& \mathrm{D}=-\frac{\mathrm{C}_{\mathrm{y}}^{\delta}\left(\mathrm{M}_{\mathrm{z}}^{\omega_{\mathrm{z}}}+\mathrm{M}_{\mathrm{z}}^{\alpha}\right)}{\mathrm{M}_{\mathrm{z}}^{\delta}\left(\mathrm{R}+\mathrm{C}_{\mathrm{y}}^{\alpha}\right)-\mathrm{M}_{\mathrm{z}}^{\alpha} \mathrm{C}_{\mathrm{y}}^{\delta}} ; \\
& C=-\frac{C_{y}^{\delta} J_{z}}{M_{z}^{\delta}\left(R+C_{y}^{\alpha}\right)-M_{z}^{\alpha} C_{y}^{\delta}} .
\end{aligned}
$$

Оскільки у розглянутій моделі постійні часу $\mathrm{T}_{1} \mathrm{i} \mathrm{T}_{2}$, як правило, мають малі значення, передаточна функція нормального прискорення ракети по куту відхилення рулів у першому наближенні описується коливальною ланкою 3 коефіцієнтом передачі $\mathrm{K}$, постійною часу $\mathrm{T}_{\alpha} \mathrm{i}$ коефіцієнтом демпфування $\xi$ [6].

Якщо знехтувати впливом аеродинамічного коефіцієнта $\mathrm{m}_{\mathrm{z}}^{\omega_{\mathrm{z}}}$, то спрощені вирази для коефіцієнта передачі по нормальному прискоренню і постійної часу керованої ракети будуть мати такий вигляд:

$$
\begin{aligned}
& \mathrm{K} \approx \frac{\frac{\mathrm{m}_{\mathrm{z}}^{\delta}}{\mathrm{m}_{\mathrm{z}}^{\alpha}}\left(\mathrm{R}+\mathrm{c}_{\mathrm{y}}^{\alpha} \frac{\rho \mathrm{V}^{2}}{2} \mathrm{~S}_{\mathrm{xap}}\right)-\mathrm{c}_{\mathrm{y}}^{\delta} \frac{\rho \mathrm{V}^{2}}{2} \mathrm{~S}_{\mathrm{xap}}}{\mathrm{m}} \\
& \mathrm{T}_{\alpha} \approx \frac{1}{\mathrm{~V}} \sqrt{\frac{2 \mathrm{~J}_{\mathrm{z}}}{-\mathrm{m}_{\mathrm{z}}^{\alpha} \rho \mathrm{S}_{\mathrm{xap}} \mathrm{L}_{\text {хар }}}}
\end{aligned}
$$

Оскільки кут відхилення рулів ракети не може перевищувати деякого максимального значення $\delta_{\max }, \quad$ максимальне усталене нормальне прискорення, яке може розвинути ракета, має 
вигляд: $\ddot{y}_{\max }=\mathrm{K} \delta_{\max }$, а прогнозоване перевантаження має вигляд відповідно: $\mathrm{n}_{\mathrm{y}_{\text {расп }}}=\frac{\mathrm{K} \delta_{\max }}{\mathrm{g}}$.

Постійна часу $\mathrm{T}_{\alpha}$ пропорційна періоду коливань та зворотно пропорційна їх частоті. Власна частота має вигляд:

$$
\omega_{\mathrm{a}}=\frac{1}{\mathrm{~T}_{\mathrm{a}}} \text { або } \mathrm{f}_{\mathrm{a}}=\frac{1}{2 \pi \mathrm{T}_{\mathrm{a}}} .
$$

Передаточна функція, що характеризує лінійне поперечне переміщення центру мас КАР в залежності від кута відхилення рулів, має вигляд:

$$
\mathrm{M}_{\delta}^{\mathrm{y}}=\mathrm{K} \frac{\left(\mathrm{T}_{1} \mathrm{P}+1\right)\left(\mathrm{T}_{2} \mathrm{P}+1\right)}{\mathrm{P}^{2}\left(\mathrm{~T}_{\alpha}^{2} \mathrm{P}^{2}+2 \xi \mathrm{T}_{\alpha} \mathrm{P}+1\right)} .
$$

При аналізі динамічних характеристик використовується передаточна функція кута атаки ракети по куту відхилення рулів.

3 урахуванням виразу (7) отримаємо:

$$
\mathrm{M}_{\delta}^{\alpha}=\mathrm{K}_{\alpha} \frac{\mathrm{T}_{3} \mathrm{P}+1}{\left(\mathrm{~T}_{\alpha}^{2} \mathrm{P}^{2}+2 \xi \mathrm{T}_{\alpha} \mathrm{P}+1\right)}
$$

де

$$
\mathrm{K}_{\alpha}=\frac{\mathrm{M}_{\mathrm{z}}^{\delta}+\mathrm{M}_{\mathrm{z}}^{\omega_{\mathrm{z}}} \frac{\mathrm{C}_{\mathrm{y}}^{\delta}}{\mathrm{mV}}}{\mathrm{M}_{\mathrm{Z}}^{\alpha}+\mathrm{M}_{\mathrm{z}}^{\omega_{\mathrm{z}}} \frac{\left(\mathrm{R}+\mathrm{C}_{\mathrm{y}}^{\alpha}\right)}{\mathrm{mV}}} ; \mathrm{T}_{3}=\frac{\mathrm{C}_{\mathrm{y}}^{\delta} \mathrm{J}_{\mathrm{z}}}{-\mathrm{M}_{\mathrm{z}}^{\delta} \mathrm{mV}-\mathrm{M}_{\mathrm{z}}^{\omega_{\mathrm{z}}} \mathrm{C}_{\mathrm{y}}^{\delta}} .
$$

Коефіцієнт передачі $\mathrm{K}_{\alpha} \quad$ характеризує залежність сталого кута атаки керованої ракети від кута відхилення рулів. Нехтуючи впливом демпфуючого моменту, отримуємо спрощений вираз для даного параметра:

$$
\mathrm{K}_{\alpha} \approx \frac{\mathrm{m}_{\mathrm{z}}^{\delta}}{\mathrm{m}_{\mathrm{z}}^{\alpha}} .
$$

Значення параметрів, що входять у вирази (8) - (14), змінюються в залежності від поточних умов польоту ракети.

Склад і структура системи управління повинні забезпечувати стабілізацію ракети як динамічної ланки 3 передаточною функцією (8) і змінними параметрами на заданій траєкторії польоту ракети в різних умовах.

Для вирішення даної задачі складається алгоритм моделювання. Алгоритм моделювання розробляється таким чином, щоб по можливості більш точно врахувати усі фактори, які впливають на політ ракети, роботу іiі системи управління та контуру наведення. Даний алгоритм можна умовно розбити на три частини: завдання початкових умов, цикл інтегрування, відображення результатів розрахунку.

На перших етапах розробки вводять розрахункові початкові умови польоту ракети (модуль i напрям вектора швидкості ракети, початкові кути тангажу, курсу, крену, кутові швидкості тощо) i розрахункові початкові параметри контуру наведення. В залежності від заданих умов пуску, відстані, швидкості і маневру повітряної цілі моделюється робота контуру наведення ракети, розраховується положення інформаційного поля в просторі.
На початковому етапі розроблення алгоритм управління ракетою може бути описаний за допомогою диференціальних рівнянь, потім ці рівняння замінюються на різницеві. На останніх етапах розроблення алгоритм управління ракетою, що введений в математичну модель, повинен повністю відповідати алгоритму, який вводиться в бортовий процесор ракети. По мірі отримання експериментальних даних модель системи управління уточнюється, до неї вводяться певні збурюючі фактори, що впливають на іiі роботу $[6,8]$.

При математичному моделюванні 3 рішення системи диференціальних рівнянь (1) - (6) визначаються поточні координати $\mathrm{y}, \mathrm{z}$ центра ваги ракети. Виходячи 3 обраного методу наведення, визначаються задані положення центру ваги $\mathrm{y}_{\text {зад }}, \mathrm{z}_{\text {зад }}$, для даного моменту часу польоту.

Поточне відхилення ракети від заданої траєкторії польоту визначається з співвідношень:

$$
\Delta \mathrm{Y}=\mathrm{y}-\mathrm{y}_{\text {зад }} ; \Delta \mathrm{Z}=\mathrm{z}-\mathrm{z}_{\text {зад }} .
$$

Припускаючи, що згладжуючий фільтр в структурній схемі формування команд ракети являє собою аперіодичну ланку 3-го порядку 3 постійною часу $\mathrm{T}_{\phi}$, спрощений алгоритм роботи формування заданих кутів відхилення рулів може бути представлений у вигляді такої системи диференціальних рівнянь $[6,9]$ :

$$
\begin{aligned}
& \mathrm{T}_{\phi}^{3} \frac{\mathrm{d}^{3} \mathrm{Y}_{1}}{\mathrm{dt}^{3}}+3 \mathrm{~T}_{\phi}^{2} \frac{\mathrm{d}^{2} \mathrm{Y}_{1}}{\mathrm{dt}^{2}}+3 \mathrm{~T}_{\phi} \frac{\mathrm{dY}_{1}}{\mathrm{dt}}=\Delta \mathrm{Y} ; \\
& \frac{\mathrm{dY}}{\mathrm{dt}}=\mathrm{K}_{\mathrm{M}}\left(\mathrm{T}_{\text {пидд }}^{2} \frac{\mathrm{d}^{2} \mathrm{Y}_{1}}{\mathrm{dt}^{2}}+2 \xi_{\text {пид }} \mathrm{T}_{\text {пид }} \frac{\mathrm{d} \mathrm{Y}_{1}}{\mathrm{dt}}+1\right) ; \\
& \mathrm{Y}_{3}=\mathrm{K}_{\mathrm{yc}} \mathrm{Y}_{2} ; \\
& \mathrm{T}_{\mathrm{a}}^{2} \frac{\mathrm{d}^{2} \mathrm{Y}_{4}}{\mathrm{dt}^{2}}+2 \mathrm{~T}_{\mathrm{a}} \frac{\mathrm{dY}_{4}}{\mathrm{dt}}+\mathrm{Y}_{4}=\mathrm{T}_{\mathrm{a}}^{2} \frac{\mathrm{d}^{2} \mathrm{Y}_{3}}{\mathrm{dt}^{2}}+2 \mathrm{~T}_{\mathrm{a}} \xi_{2} \frac{\mathrm{d} \mathrm{Y_{3 }}}{\mathrm{dt}}+\mathrm{Y}_{3} ; \\
& \delta_{\mathrm{y}}=\mathrm{Y}_{4}+\delta_{\text {кв }} ; \\
& \mathrm{T}_{\phi}^{3} \frac{\mathrm{d}^{3} \mathrm{Z}_{1}}{\mathrm{dt}^{3}}+3 \mathrm{~T}_{\phi}^{2} \frac{\mathrm{d}^{2} \mathrm{Z}_{1}}{\mathrm{dt}^{2}}+3 \mathrm{~T}_{\phi} \frac{\mathrm{dZ}_{1}}{\mathrm{dt}}=\Delta \mathrm{Z} ; \\
& \frac{\mathrm{dZ}_{2}}{\mathrm{dt}^{2}}=\mathrm{K}_{\mathrm{M}}\left(\mathrm{T}_{\text {пид }}^{2} \frac{\mathrm{d}^{2} \mathrm{Z}_{1}}{\mathrm{dt}^{2}}+2 \xi_{\text {пид }} \mathrm{T}_{\text {пид }} \frac{\mathrm{d} \mathrm{Z}_{1}}{\mathrm{dt}}+1\right) ; \\
& \mathrm{Z}_{3}=\mathrm{K}_{\mathrm{yc}} \mathrm{Z}_{2} ; \\
& \mathrm{T}_{\mathrm{a}}^{2} \frac{\mathrm{d}^{2} \mathrm{Z}_{4}}{\mathrm{dt}^{2}}+2 \mathrm{~T}_{\mathrm{a}} \frac{\mathrm{dZ}_{4}}{\mathrm{dt}}+\mathrm{Y}_{4}=\mathrm{T}_{\mathrm{a}}^{2} \frac{\mathrm{d}^{2} \mathrm{Z}_{3}}{\mathrm{dt}^{2}}+2 \mathrm{~T}_{\mathrm{a}} \xi_{2} \frac{\mathrm{d} \mathrm{Z}_{3}}{\mathrm{dt}}+\mathrm{Z}_{3} ; \\
& \delta_{\mathrm{z}}=\mathrm{Z}_{4} \cdot
\end{aligned}
$$

Для управління рульовими поверхнями (сигнали $\delta_{\mathrm{y}}, \delta_{\mathrm{z}}$ ) ракети використовують схему, яка наведена на рис. 3 .

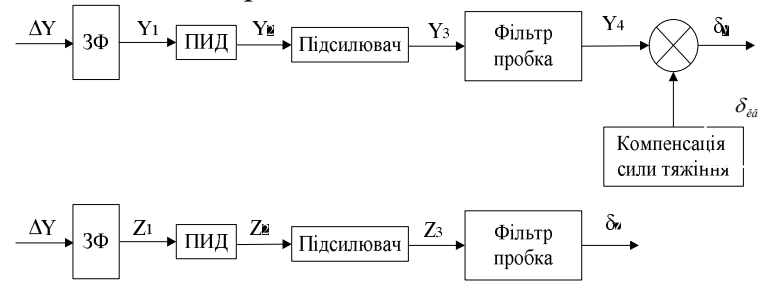

Рис. 3. Структурна схема формування команд управління (ЗФ - фільтр, що згладжує; ПІД регулятор параметрів управління) 
При цьому сигнали $\delta_{\mathrm{y}}, \delta_{\mathrm{z}}$ представляють собою задані амплітуди відхилення аеродинамічних рулів ракети у вертикальній i горизонтальній площинах, а сигнал $\delta_{\text {кв }}-$ команду компенсації сили тяжіння. Сигнали $\delta_{\mathrm{y}}, \delta_{\mathrm{z}}$ згідно структурної схеми, що наведена на рис. 4, надходять на вхід синусно-косинусного перетворювача.

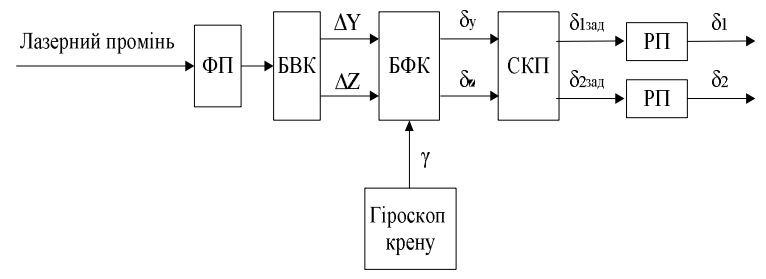

Рис. 4. Структурна схема системи керування (ФП - фотоприймальний пристрій, БВК - блок виділення координат, БФК - блок формування команд,СКП - синусно-косинусний перетворювач,

$$
\text { РП - рульовий привід) }
$$

3 урахуванням поточного кута крену ракети $\gamma$, значення якого визначається 3 системи рівнянь (1) - (6), перетворюються в задані кути відхилення аеродинамічних рулів ракети:

$$
\begin{aligned}
& \delta_{\text {1зад }}=\delta_{\mathrm{y}} \cos \gamma+\delta_{\mathrm{z}} \sin \gamma ; \\
& \delta_{\text {2зад }}=-\delta_{\mathrm{y}} \sin \gamma+\delta_{\mathrm{z}} \cos \gamma .
\end{aligned}
$$

Оскільки динамічні характеристики рульового приводу близькі до характеристик коливальної ланки 3 постійною часу $\mathrm{T}_{\text {пр }} \mathrm{i}$ коефіцієнтом

\section{Jimepamypa}

1. Архіпов М.I. Станція оптико-електронного придушення "Адрос" КТ - 01 ABE / M.I. Архіпов. [Електронний ресурс]. - Режим доступу: http://adron.ua. 2. Бесекерский В.А., Попов Е.П. Теория систем автоматического управления / В.А. Бесекерский, Е.П Попов. - Изд. 4-е, перераб. и доп. - С-Пб.: Изд-во "Профессия", 2003. - 752 с. 3. Бортовой комплекс обороны "Талисман" [Электронный ресурс]. - Режим доступа к материалу: http: // defin.by /products / talisman. 4. Дорф Р., Бишоп Р. Современные системы управления / пер. с англ. Б.И. Копылова. - М.: Лаборатория базовых знаний, 2002. - 832 с. 5. Евграфов В.Г. Системы и средства РЭБ самолётов тактической авиации $\mathrm{BC}$ зарубежных государств. Зарубежное военное обозрение. - М.: ОАО Издательский дом "Красная звезда", 2006. -№9.-С.4447. 6. Коростельов О.П. Теоретичні основи проектування ствольних керованих ракет / [Коростельов О.П., Доценко Б.І., Качаєв М.А. та ін.] під ред. О.П. Коростельова. - К.: Вид. Defense express library, 2007. 445 с. 7. Коротін С.М. Методика визначення ефективності застосування керованих авіаційних ракет класу “повітря-повітря" ближньої дії по повітряним цілям / C.М. Коротін. Збірник наукових праць інституту проблем моделювання в енергетиці ім. Г.С. Пухова НАН України, - К., 2013. - Вип. 66 - С.25-35. загасання $\xi_{\text {пр }}$, поточні кути $\delta_{1}, \delta_{2}$ відхилення аеродинамічних рулів керованої ракети можна визначити $з$ рівнянь:

$$
\begin{aligned}
& \delta_{\text {1зад }}=\mathrm{T}_{\text {пр }}^{2} \frac{\mathrm{d}^{2} \delta_{1}}{\mathrm{dt}^{2}}+2 \mathrm{~T}_{\text {пр }} \xi_{\text {пр }} \frac{\mathrm{d} \delta_{1}}{\mathrm{dt}}+\delta_{1} ; \\
& \delta_{2 \text { зад }}=\mathrm{T}_{\text {пр }}^{2} \frac{\mathrm{d}^{2} \delta_{2}}{\mathrm{dt}^{2}}+2 \mathrm{~T}_{\text {пр }} \xi_{\text {пр }} \frac{\mathrm{d} \delta_{2}}{\mathrm{dt}}+\delta_{2} .
\end{aligned}
$$

Знаючи поточні кути відхилення рулів, та виходячи $з$ аеродинамічних характеристик ракети, часу і умов польоту, можна визначити значення сил і моментів, що діють на ракету, розрахувати прогнозовані точнісні показники тощо.

\section{Висновки й перспективи подальших} досліджень

У статті приведено прогнозну математичну модель у вигляді системи динамічних, кінематичних рівнянь руху центру мас та обертального руху гіпотетичної керованої авіаційної ракети відносно швидкісної системи координат, за результатами рішення якої отримані передаточні функції, що характеризують реакцію поперечного прискорення ракети.

Загальне рішення системи рівнянь (1) - (6) і (15) - (17), дає можливість визначити вимоги до аеродинамічних, масо-інерційних характеристик гіпотетичної керованої авіаційної ракети, удосконалити алгоритм управління, розробити вимоги до складових частин системи управління $\mathrm{i}$ зовнішнього контуру наведення, визначати промах в певних умовах їі застосування та визначити точність наведення на повітряну ціль.

8. Красовский А.А. Системы автоматического управления летательных аппаратов / А.А. Красовский, Ю.А. Вавилов, А.И. Сучков. - М.: ВВАИА им. Н.Е. Жуковского, 1985. - 478 с. 9. Лебедев А.А. Динамика полета беспилотных летательных аппаратов / A.А. Лебедев, Л.С. Чернобровкин. Учебное пособие для вузов. - Издание 2-е, переработанное и дополненное. Москва: Машиностроение, 1973. - 616 с. 10. Птичкин С.И. "Президент" активной защиты. "Российская газета", 2010. - [Електронний ресурс]. - Режим доступу: www.rg.ru. 11. Семенов С.С. Оценка технического уровня образцов вооружения и военной техники / Семенов С.С., Харчев В.Н., Иоффин А.И. - М.: Радио и связь, 2004 - 546 с. 12. Федосов Е.А. Состояние и перспективы развития оружия класса "воздух-воздух" для самолетов 5-го поколоения / [Давыдов А.Н., Черных Л.Г., Панкратов О.Н., Чабанов, В.А.] под. общ. ред. Академіка РАН Е.А. Федосова. - М.: Научноинформационный центр ГосНИИАС, 2004. - 92 с. 13. Ackermann Rainer. Current Trends in Electronic SelfProtection of Helicopters and Fixed-Wing Aircraft // Military Technology, 2002. - № 11. - P. 59. 14. Fiszer Michal. Journal of Electronic Defense / Fiszer, Michal; Gruszczynski, Jerzy. New self-protection suite and deployment for Dutch Apaches. Alexandria, Virginia. VA 22314-1652, 2004. - № 4. - P. 35 - 38.

\section{ПРОГНОЗНАЯ МАТЕМАТИЧЕСКАЯ МОДЕЛЬ УПРАВЛЕНИЯ ГИПОТЕТИЧЕСКОЙ ПЕРСПЕКТИВНОИ УПРАВЛЯЕМОИ АВИАЦИОННОИ РАКЕТОЙ}

Сергей Михайлович Коротин (канд. техн. наук, заместитель начальника кафедры) Юрий Николаевич Коломиєц (адъюнкт кафедры)

\section{Национальный университет обороны Украины имени Ивана Черняховского, Киев, Украина}


Проиесс поиска путей разработки високоэффективной управляемой авиационной ракеть, к тому же достаточно дешевой в производстве, в последние пять лет стал предметом научньх исследований науково-исследовательских организаций Министерства обороны и государственных предприятий оборонно-промышленности комплекса Украины. Считается, что одним из перспективных направлений исследований есть процес наведения такой ракеты на иель противника в поле лазерного излучения. Результаты проведенного анализа боевых возможностей и тактико-технических характеристик прототипов, которые разработань в передовых странах мира, дали возможность авторам статьи прийти к выводу о необходимости разработки моделі управления гипотетической перспективной управляемой авиационной ракетой в поле лазерного излучения. В статье представлена такая прогнозная математическая модель управления гипотетической перспективной управляемой авиационной ракетой в поле лазерного излучения. Данная математическая модель базируется на решении системь динамических и кинематических дифференщиальных уравнений. Применение данной модели позволяет определить требования $\kappa$ аэродинамическим, массо-инерииионных характеристик ракеты, усовершенствовать алгоритм управления, разработать требования к составным частям системьл управления и внешнего контура наведения, в дальнейшем корректировать алгоритм управления с учетом реально полученных характеристик перспективной управляемой ракеть, параметров элементов системы управления и контура наведения.

Ключевые слова: система управления ракеты, математическая модель, алгоритм управления.

\title{
THE PREDICTIVE MATHEMATICAL MODEL OF CONTROL OF THE HYPOTHETICAL GUIDED AVIATION MISSILE
}

\author{
Sergii M. Korotin (PhD of Technical Sciences, Deputy head of the department) \\ Yurii M. Kolomiets (associate of the department)
}

\section{National Defence University of Ukraine named after Ivan Cherniakhovsky, Kyiv, Ukraine}

The process of finding ways to develop a highly efficient guided aviation missile, besides being cheap in production, has become the subject of scientific research of the Ministry of Defense research institutions and state enterprises of the defense industry of Ukraine over the last five years along. It is believed that one of the most promising directions of research is the process of targeting such a missile to the enemy's target in the laser beam. The results of the analysis of combat properties, tactical and technical characteristics of prototypes that were developed in the leading countries of the world, allowed the authors of the article to come to a conclusion on the development of a mathematical model of management of a hypothetical perspective, guided aviation missile in the field of laser radiation. There is a predictive mathematical model of control in the laser radiation field of the hypothetical advanced guided missile. This mathematical model is based on a solution of dynamic and kinematic differential equations system. The application of the model allows to define the requirements to the aerodynamic, mass-inertial characteristics of the missile, to improve the control algorithm, to develop the requirements to the components of the control system and the external guidance contour, to adjust the control algorithm taking into account the real characteristics of the missile, the parameters of the control system elements and guidance contour.

Keywords: system of the missile control, mathematical model, algorithm of control.

\section{References}

1. Arkhipov M.I. The optoelectronic suppression station "Adros" KT - 01 AVE [Stantsiia optyko-elektronnoho prydushennia "Adros" KT - 01 AVE] / M.I. Arkhipov. Available: http://adron.ua. 2. Besekersky V.A, Popov E.P. The theory of automatic control systems / Besekersky V.A., Popov E.P. The theory of automatic control systems [Teoryia system avtomatycheskoho upravlenyia] / V.A. Besekersky, E.P. Popov. - Ed. 4th, rev. and upd. - S-PB.: Publishing House "Profession", 2003. - 752 p. 3. The onboard defense complex "Talisman" [Electronic resource]. - Available: http: // defin.by /products / talisman. 4. Dorf R., Byshop R. Modern control systems [Sovremennyie sistemyi upravleniya] / transl. from English by B.I. Kopylov. - M.: Laboratory of basic knowledge, 2002. - 832 p. 5. Evgrafov V.G. Systems and means of electronic warfare of Armed Forces tactical aircraft in the foreign countries [Sistemyi i sredstva REB samolyotov takticheskoy aviatsii VS zarubezhnyih gosudarstv]. Foreign military review. - M.: OSS Krasnaya Zvezda Publishing House, 2006 .- №9 .- P.44 47. 6. Korostelev O.P. The theoretical bases for designing guided missiles [Teoretychni osnovy proektuvannia stvolnykh kerovanykh raket] / [Korostelev O.P., Dotsenko B.I., Kachaev M.A.] under the general editorship O.P. Korostelev - K.: View. Defense express library, 2007. - 445 p. 7. Korotin S.M. Method for determining the effectiveness of the used of the missiles air-to-air for air targets [Metodyka vyznachennia efektyvnosti zastosuvannia kerovanykh aviatsiinykh raket klasu "povitria-povitria" blyzhnoi dii po povitrianym tsiliam] / S.M. Korotin. Collection of scientific works of the Modeling Problems in the energy Institute named after G.E. Puhov NAS of Ukraine - K., 2013.-№.66. - p.25-35.

8. Krasovskii A.A. Automatic control systems of aircrafts [Sistemyi avtomaticheskogo upravleniya letatelnyih apparatov] / A.A. Krasovsky, Yu.A. Vavilov, A.I. Knots. - M.: HMAIA named after. N.E. Zhukovsky, 1985. - 478 p. 9. Lebedev A.A. Flight dynamics of unmanned aircrafts [Dinamika poleta bespilotnyih letatelnyih apparatov] / A.A. Lebedev, L.S. Chernobrovkin. Textbook for universities. - Edition $2^{\text {nd }}$, revised and upd. - Moscow: Mechanical Bilding, 1973. - 616 p. 10. Ptichkin S.I. "President" of active protiction ["Prezident" aktivnoy zaschityi]. "Rossiyskaya Gazeta", 2010. - [Electronic resource]. - Available:http://nevskii-bastion.ru/president-s2015/. 11. Semenov S.S. Evaluation of the technical level of weapons and military equipment [Otsenka tehnicheskogo urovnya obraztsov vooruzheniya i voennoy tehniki] / Semenov S.S., Kharchev V.N., Ioffin A.I. - M.: Radio and communications, $2004-546$ p. 12. Fedosov E.A. The state and prospects for the development of air-to-air weapons for airplanes of the 5th generation [Sostoyanie i perspektivyi razvitiya oruzhiya klassa "vozduh-vozduh" dlya samoletov 5-go pokoloeniya] / [Davydov A.N., Chernykh L.G, Pankratov O.N, Chabanov V.A], under the general editorship of Academic RAS E.A. Fedosov. - M.: Scientific Information Center S.S.R.I. of Aviation System, 2004. - 92 p. 13. Ackermann Rainer. Current Trends in Electronic Self-Protection of Helicopters and Fixed-Wing Aircraft // Military Technology, 2002. - № 11. P. 59. 14. Fiszer Michal. Journal of Electronic Defense / Fiszer, Michal; Gruszczynski, Jerzy. New self-protection suite and deployment for Dutch Apaches. Alexandria, Virginia. VA 22314-1652, 2004. -№ 4. - P.35-38. 